\title{
TRADUÇÃO LITERÁRIA E DISCUSSÃO ESTÉTICA: CRIANDO E RECRIANDO FELICIDADE
}

\author{
Leila Cristina Mello Darin* \\ Pontifícia Universidade Católica de São Paulo
}

\begin{abstract}
Resumo: Este artigo procura mostrar que o exame crítico do processo de tradução literária pode contribuir de forma significativa para a compreensão do processo que conduz à criação de obras poéticas. $\mathrm{O}$ material literário que inspira essa discussão é a tradução para o português do conto "Bliss" (1918), da escritora neozelandesa Katherine Mansfield, realizada pela poeta brasileira Ana Cristina Cesar. São também consideradas para análise as 80 notas que a tradutora elaborou a respeito de sua versão do conto, intitulada Extase, as quais elucidam e ilustram os critérios que norteiam suas soluções tradutórias. A discussão corrobora a tese de que criar e recriar são atividades afins, guiadas por princípios estéticos que revelam uma grande paixão pelas palavras.
\end{abstract}

Palavras-chave: Tradução Literária. Katherine Mansfield. Ana Cristina Cesar. "Bliss". "Êxtase".

\footnotetext{
* Possui graduação em Língua e Literatura Inglesas pela Pontifícia Universidade Católica de São Paulo (1977), mestrado em Linguística Geral Descritiva e Aplicada - Exeter University (1986) e doutorado em Comunicação e Semiótica pela Pontifícia Universidade Católica de São Paulo (1993). Atualmente é professora titular da Pontifícia Universidade Católica de São Paulo, onde ministra aulas no curso de Letras-Tradução Inglês/Português. São Paulo, SP, Brasil. E-mail: ldarin@uol.com.br
} 


\title{
LITERARY TRANSLATION AND AESTHETIC DEBATE: CREATING AND RECREATING BLISS
}

\begin{abstract}
The present article aims to show that the critical examination of the process of literary translation can contribute significantly to the understanding of the process that leads to the writing of poetic works. The literary material used to inspire our discussion is Brazilian poet Ana Cristina Cesar's translation into Portuguese of the short story "Bliss" (1918), by New Zealander writer Katherine Mansfield. The material includes 80 notes on the translation of the short story, entitled "Êxtase", written by Cesar herself, which clarify and illustrate the criteria that guide her translation choices. The analysis highlights that writing and rewriting are related activities, led by aesthetic principles that reveal a great passion for words.
\end{abstract}

Kewords: Literary Translation. Katherine Mansfield. Ana Cristina Cesar. "Bliss". "Êxtase".

\section{Introdução à discussão}

O escritor argentino Jorge Luis Borges inicia seu conhecido ensaio “As Versões Homéricas” (1932) com uma intrigante reflexão sobre a natureza e função da tradução literária. Borges afirma que, enquanto o processo de criação de uma obra de literatura é, em geral, envolto em "uma reserva incalculável de sombra", a tradução, por sua vez, "parece destinada a ilustrar a discussão estética" (BORGES, 1986, p. 71). São muitas as implicações dessa asserção, e aqui desejamos destacar uma delas: o processo de produção do texto original - ao qual Borges se refere como "escrita direta"- deixa de ser considerado a única e principal fonte de estudo e indagação sobre o literário, passando o foco a ser o movimento de reconstrução literária do texto poético dito "original".

De fato, o olhar atento à reescrita literária evidencia o quão próximos se encontram os processos de escrever e de traduzir literatura. Dada à natureza dialógica que estabelece com o texto original, a tradução de um texto literário, uma vez editada e publicada em 
um veículo próprio a sua divulgação, convida ao exame, análise, comparação e crítica do trabalho artístico realizado com a língua e a cultura para a qual se traduz, relativamente à recriação dos procedimentos literários empregados na obra de referência.

Iniciamos nossa reflexão sobre os processos de escrita e reescrita literária, com a discussão, ainda que breve, das ideias de José Paulo Paes sobre a atividade tradutória do poeta Manuel Bandeira, expostas no ensaio intitulado "Bandeira tradutor ou o esquizofrênico incompleto" (1990). Nele, Paes afirma que Bandeira, tradutor de poesia do francês, inglês, alemão e espanhol, teria expressado a grande dificuldade - e mesmo a impossibilidade - de autotraduzir-se do francês para o português.

Paes se surpreende com o fato de Bandeira ser capaz de escrever um poema, mas não de traduzi-lo, cogitando, inclusive, da possibilidade de uma dissociação entre o Bandeira poeta e o Bandeira tradutor de poesia, principalmente porque, conforme salienta o autor, Bandeira, em seus comentários, dava mostras de que seu trabalho de tradutor de poesia não diferia substancialmente de seu labor de poeta.

Então, como interpretar o fato de Bandeira não lograr autotraduzir-se, a despeito de sua óbvia familiaridade com a língua portuguesa, mas ter sido altamente elogiado pelo crítico Abgar Renault por suas traduções poéticas para o inglês, dos sonetos de Elizabeth Barret Browning, quanto às sutilezas, nuanças de significado e expressões idiomáticas? Bandeira responde à crítica elogiosa de Renault afirmando conhecer apenas superficialmente a língua inglesa e explicando suas soluções bem sucedidas da seguinte maneira:

devem se ter processado no subconsciente, porque as traduções me saíram quase ao correr do lápis. Antes houve, sim, o que costumo fazer sempre quando traduzo: deixar o poema como que flutuar por algum tempo dentro do meu espirito, à espera de certos pontos de fixação... Os meus 'achados', em traduções como em originais, resultam sempre de intuições. (BANDEIRA, apud Paes, 1990, p. 58). 
Vê-se, nessa afirmação, que Bandeira situa escrever e traduzir no mesmo patamar: ambos decorrem de sua intuição de poeta, isto é, procedem de imersão no subconsciente, sendo gestados por caminhos aos quais o poeta tradutor não tem acesso. Também quando fala da dificuldade que sentiu para traduzir nove poemas do poeta alemão F. Holderlin, Bandeira refere-se ao trabalho como "uma das maiores batalhas que pelejei na minha vida de poeta" (apud Paes, 1990, p. 57). Isso mostra claramente que ele entende escrever e traduzir como práticas poéticas. $\mathrm{O}$ fato de sua atividade de tradução merecer críticas e conjecturas corrobora a tese borgeana de que a tradução está destinada ao debate estético.

Sobre a dificuldade de autotradução, a conclusão de Paes é desconcertante: ele a considera resultado da ideia - de fato expressa por Bandeira-, de que poesia é intraduzível; contudo, tal conclusão não se sustenta diante da exitosa experiência tradutória do poeta, e da evidência de que sua prática está alicerçada no princípio da tradução como recriação (CAMPOS, 1977) e como equivalência na diferença (JAKOBSON, 1959). José Paulo Paes chega a conceber um descompasso entre o poeta criador e o artesão tradutor, argumentando que o tradutor é, "no limite, um recriador, com um estatuto necessariamente de inferioridade em relação ao criador" (1990, p. 65).

Entretanto, parece-nos que Paes utiliza o caso da autotradução bandeiriana para ilustrar sua própria visão de língua e tradução. Já os depoimentos de Bandeira indicam uma profícua relação entre escrever e traduzir, como se vê em Andorinha, andorinha (1978): "A tradução de um poema é, afinal de contas, uma recriação. Assim que ela só é total e perfeita quando sai fiel ao poeta traduzido e fiel ao poeta tradutor" (apud Prado, 2011 p. 161). Ao contrário de Paes, Bandeira não prega haver uma distinção hierárquica entre criação e recriação; para ele, os dois processos são frutos da arte de trabalhar as formas e sentidos das línguas. Tal percepção é corroborada pela pesquisadora Célia Prado, em seu artigo "Tradução, Paródia e paráfrase: as reescrituras poéticas de Manuel Bandeira" (2011): Assim como para Campos o trabalho de tradutor por ser 
tributário da atividade primeira não é secundário, pois é também criativo, em Bandeira também se observa uma interdependência produtiva entre o fazer poético e o traduzir. (PRADO, 2011, p. 163 , nosso grifo)

Se as duas atividades lhe eram, de fato, tão próximas, seria possível considerar a hipótese de que Manuel Bandeira talvez não se sentisse à vontade para refazer, em outro idioma, o caminho que ele mesmo desbravara como poeta. De qualquer modo, a dificuldade de autotraduzir-se nos parece ter origem em sua forma peculiar e pessoal de vivenciar as relações entre criação e recriação.

\section{Ana Cesar, poeta e tradutora}

Para adensar a discussão, examinaremos, a seguir, o estudo realizado em 1981 pela poeta e tradutora Ana Cristina Cesar, no qual discute sua tradução para o português do conto "Bliss" (1920), da escritora neozelandesa Katherine Mansfield (ou Kathleen Manfield Beauchamp). Embora o conto tenha outras traduções1, escolhemos retrilhar o percurso tradutório de Ana Cesar porque a análise que realizou sobre seu próprio trabalho oferece material instigante para a reflexão sobre a íntima ligação entre os processos literários de escrita e de tradução. A tradução comentada do conto foi objeto de sua pesquisa de Mestrado em Teoria e Prática de Tradução Literária na Universidade de Essex, Inglaterra, em 1981. Esse e outros textos de Ana Cristina foram traduzidos e publicados postumamente por sua mãe, Maria Luiza Cesar, sob o título de Escritos da Inglaterra (1988).

O objetivo inicial da dissertação, intitulada "O conto 'Bliss', Anotado", foi explorar questões suscitadas pela tradução do conto, por meio de notas de pé de página. No entanto, as notas ou anotações, inicialmente pensadas como comentários relativamente marginais, acabaram assumindo o centro do trabalho e, segundo a autora, 
foram desvendando gradualmente a forma como o processo de tradução se estava efetuando; elas convergem, passo a passo, para os movimentos da mão e da mente do tradutor, incluindo digressões que não são eruditas, problemas de interpretação literária e algumas perplexidades sobre os próprios personagens, que não puderam ser adequadamente resolvidas. (1988, p. 12, nosso grifo).

O caráter analítico das notas torna-se ainda mais interessante pela forma "honesta" e "despretensiosa" como a tradutora ensaísta expõe suas dúvidas e impasses ${ }^{2}$ - uma qualidade que grande parte dos tradutores literários parece não demonstrar. Ao invés de assumir a máscara da invisibilidade e modéstia de tantos tradutores de literatura, Ana Cesar exerce seu poder de escritora e não hesita em fazer opções com base em sua leitura e em seu talento de poeta. Desde o momento em que a pesquisa foi divulgada, suas considerações estimularam inúmeros estudos ${ }^{3}$, tornando-se uma referência para o estudo da tradução de textos literários e da escrita literária. Frisamos que as Notas de Ana Cristina Cesar ilustram de modo exemplar o postulado de Borges em "As Versões Homéricas”, a respeito do valor da escrita indireta para a percepção e o discernimento dos mecanismos de criação literária.

Pode-se dizer que o vínculo precoce com as Letras, e o fato de Ana C. Cesar ter sido poeta (A teus pés, 1982; Inéditos e Dispersos, 1985), permitiram à tradutora desenvolver uma sensibilidade aguçada para os fenômenos da linguagem, bem como o olhar crítico e a criatividade tão caros à tradução literária. Muitos pesquisadores postulam a mútua irrigação entre as duas artes, da qual Ana Cesar teria se beneficiado: "A tarefa de tradutora mantém um vínculo muito forte com o exercício da poesia: não só a poeta Ana Cristina influenciará a tradutora, mas esta também estimulará o amadurecimento da escritora". (SOUZA, 2010, p. 22). 


\section{Operações Gêmeas}

Já nos instruiu Octavio Paz (1980) que a atividade do tradutor é paralela à do poeta, dado que ambos trabalham com signos em movimento, sejam eles escolhidos pelo poeta a partir da língua em estado de livre circulação, em plena fonte - na língua fonte-, quer sejam eles extraídos de um texto "pronto" e devolvidos à vida da linguagem, à língua outra, meta do tradutor. "Em seus dois momentos a tradução é uma operação paralela, ainda que em sentido inverso, à criação poética”, conclui o ensaísta (2009, p. 27).

Como poeta e tradutora, Ana Cesar sente-se à vontade para discorrer sobre trabalho, inclusive sobre os pressupostos que partilhava no final dos anos 70 e início dos 80 , situando o leitor sobre seu projeto e seu engajamento no momento histórico no qual se inseria. Duas grandes fontes de inspiração são explicitadas pela tradutora: os irmãos Campos e Manuel Bandeira. Os poetas concretistas Augusto e Haroldo de Campos tornaram-se conhecidos por inovarem a prática tradutória por meio da importação, para o sistema literário brasileiro, de autores como Pound, Donne, Maiakovski, Mallarmé, Ungaretti, Bashô, que renovaram, cada qual a sua maneira, o estilo poético de seu tempo e lugar. O projeto dos Campos seguia uma orientação ideológica que caminhava na contramão da prática literária vigente no Brasil à época.

A importância dos dois tradutores para Ana Cesar vê-se retratada em "Bastidores da Tradução" que integra Escritos da Inglaterra, onde é abordada a proposta tradutória de A. de Campos: "Augusto de Campos dará preferência àqueles poetas que 'lutaram por um estandarte e lema radicais: intervenção e rigor" (1988, p. 144). Ao expandir a respeito dessa preferência, a ensaísta assinala três qualidades inerentes ao rigor formal: densidade, concisão e precisão - atributos que irá enfatizar em sua tradução de "Bliss". Na Nota 9 de seu estudo, por exemplo, seus comentários revelam a preocupação com a redução de adjetivos e a opção por palavras "bastante exatas e expressivas": 
"But in her bosom there was still that bright glowing place - that shower of little sparks coming from it.

"Mas no seu peito ainda havia aquela ardência - aquela irradiação de centelhas que queimavam”. (CESAR, 1988, p. 59).

Graças à condensação de expressões como "that bright glowing place" por "aquela ardência", e de "that shower of little sparks coming from it" por "aquela irradiação de centelhas que queimavam”, a frase do inglês, de 19 palavras, ganhou uma excelente tradução de apenas 14 termos em português, revelando o foco da poeta tradutora na precisão, concisão e economia. O desejo por tornar o texto do conto mais enxuto e sintético, mas igualmente eloquente na língua portuguesa, inspira-se, conforme esclarece a tradutora, na economia da língua inglesa; além disso, a opção pela forma concisa, bela e expressiva se coaduna com o estilo de $\mathrm{K}$. Mansfield, como veremos adiante.

Em relação às traduções de Augusto Campos, contudo, a tradutora manifesta um posicionamento crítico, pois, apesar de considerar que haja nas traduções "grandes soluções poéticas" que são "bastante engenhosas", avalia que o resultado é, em alguns casos, uma "charada intelectual" (1988, p. 147 e 149) que contradiz a cadência musical da linguagem poética - outro aspecto fortemente presente nas preocupações da tradutora. Nesse sentido, Ana Cesar aproxima-se de Manuel Bandeira, cujo envolvimento com os sentimentos ocorrem, segundo ela, "sem qualquer reticência, mesmo que o resultado não se revele tão arguto e habilidoso, na tradução" (1988, p. 150).

Em suas Notas, a tradutora não oculta suas reações e sentimentos em relação às palavras e estruturas das frases. Isso se pode verificar, por exemplo, em: “Aqui há duas alternativas de tradução perfeitamente válidas: 'to float in the air': 'soltos no ar' e 'flutuar no espaço'. Escolhi a primeira forma porque sugeria mais mistério e era mais simples" (1988, p. 62). Também se vê na justificativa para o emprego de algumas palavras, como na Nota 16: "Chamo a atenção do leitor para essa linda palavra la- 
tina paene: quase/almost + umbra: sombra/shadow - originando penumbra." (idem, ibidem).

O título "O Conto 'Bliss' Anotado", que Ana Cesar dá a sua dissertação, vem seguido de um segundo título que resume muito bem suas diretrizes norteadoras: "PAIXÃO E TÉCNICA: tradução, em língua em portuguesa, do conto 'Bliss' de Katherine Mansfield, seguida de 80 anotações". Paixão e técnica lembram a noção de intelletto d'amore, à qual se refere Haroldo de Campos em "Da tradução como criação e como crítica" (1970), quando descreve a forma como foram feitas traduções de "textos difíceis". Para o concretista, a tradução poética é "antes de tudo uma vivência interior do mundo e da técnica do traduzido" que traz à luz "aquela fragílima beleza num corpo linguístico diverso.” (CAMPOS, 1970, p. 43).

A aliança entre emoção e rigor técnico - que expressa a conciliação singular das concepções poéticas de Bandeira e dos Campos - é a força que move a tradutora. O processo de tradução de "Bliss" dá testemunho do entrelaçamento dessas duas diretrizes: o ritmo, aspecto ligado à emoção, está intimamente ligado a escolhas sintáticas e sintéticas que espelham a estrutura do inglês e, ao mesmo tempo, respeitam a estrutura da língua portuguesa. Conforme afirma a tradutora, a maior parte das Notas partiu de seu foco na concisão, em função de o português ser menos econômico que o inglês e da falta de correspondência entre os idiomas.

Esse procedimento incluiu a supressão consciente de pronomes supérfluos, a condensação de dois ou três períodos diferentes através de estruturas subordinativas e, às vezes, a alteração na ordem das palavras, para se conseguir melhor ritmo e tensão. Na realidade, creio que o interesse pelo ritmo da prosa estava sempre orientando toda e qualquer intervenção sintática [...]. (CESAR, 1988, p. 13-14, nosso grifo).

Na seção final do livro de 1988, somos presenteados com um ensaio curto no qual teoriza sobre suas traduções de alguns poemas 
e nos deparamos, mais uma vez, com o princípio chave de sua escrita poética: "Concentração versus Inflação". Ciente de que a tradução para outro idioma tende a explicitar a "inerência semântica" do texto de origem, isto é, a dizer mais, afirma que no caso de poemas curtos um dos grandes desafios do tradutor é "reduzir a taxa de inflação ao mínimo", sem deixar de procurar equivalências para o significado.

Um dos poemas traduzidos por Ana Cesar é "Words”, de Sylvia Plath, do qual nos oferece uma tradução intermediária e a final. Para os que amam a força do verbal, Palavras é belo e impactante. Diz a tradutora sobre o poema em português (CESAR, 1988, p. 163): "penso que minha tradução conseguiu, sem perdas substanciais, ser até mesmo mais condensada do que o texto original, em alguns aspectos". Para atestar a veracidade dessa avaliação, vejamos a primeira estrofe (CESAR, 1988, p. 172-173):

\section{Words}

Axes, After whose stroke the wood rings, And the echoes!

Echoes travelling

Off from the centre like horses.

\section{Palavras}

Golpes, De machado na madeira. E os ecos! Ecos que partem A galope.

Tal como Manuel Bandeira, Ana Cesar recorre ao mesmo manancial para criar e recriar linguagem artística. E como o poeta modernista, seu talento para a literatura não tem fronteiras: se presentifica sempre que ela escreve. Flora Sussekind (1995) considera que o conjunto das produções de Ana Cesar revela o quanto sua atividade de poeta encontra-se próxima à tradutora e quanto a prática da tradução contribuiu "para o aprimoramento de seu método poético. Em alguns casos, tratava-se de traduzir para observar mais de perto este ou aquele traço estilístico, esquema rítmico ou imagem recorrente" (apud GOMES, 2006 s/p). 


\section{Almas gêmeas}

As afinidades entre Ana Cesar e a escritora Katherine Mansfield, nascida na Nova Zelândia (1888- 1923), já foram apontadas em estudos anteriores. Mais além dos aspectos biográficos que aproximam as duas escritoras4, salienta-se o interesse de Ana Cesar pela temática da contista neozelandesa. Conforme ponderam Gomes e Oliveira, a escolha de Ana Cesar por resgatar um conto publicado em 1920 deve-se à temática que antecipa "questionamentos comuns à contemporaneidade, a saber, a dificuldade de representação de papéis fixos, a reivindicação da possibilidade de se transitar entre espaços, sem necessariamente se deter em um ponto específico, de se ocupar um espaço liminar." (GOMES e OLIVEIRA, 2009, p. 44).

Além disso, e mais importante para nós, Ana Cesar deixa clara sua proximidade com as prioridades estéticas de Mansfield ao escolher para prefaciar sua pesquisa de Mestrado a seguinte citação da contista: "Tenho paixão pela técnica. Tenho paixão em transformar o que estou fazendo em algo completo - se é que me entendem. Acredito que é da técnica que nasce o verdadeiro estilo. Não há atalhos nesse caminho". (MANSFIELD apud CESAR, 1988, p. 10)

A ênfase manifestada por Mansfield ao ritmo e à arquitetura sintática para a construção da prosa poética é partilhada por Cesar. De fato, a segunda citação da contista de língua inglesa, que consta do prefácio de "O conto "Bliss" anotado", poderia bem ter sido redigida por Ana Cesar:

Escolhi não apenas o comprimento de cada frase, mas até mesmo o som de cada frase. Escolhi a cadência de cada parágrafo, até conseguir que eles ficassem inteiramente ajustados às frases, criados para elas naquele exato dia e momento. Depois, leio o que escrevi em voz alta - inúmeras vezes -, como alguém que estivesse repassando uma peça musical - tentando chegar cada vez mais perto da expressão perfeita, até lograr alcançá-la por completo. (MANSFIELD apud CESAR, 1988, p. 10). 
A afinidade de Ana Cesar com os preceitos literários de Mansfield e sua capacidade de acompanhar os movimentos da criação da contista transparecem em "Êxtase". Segundo relata em Escritos na Inglaterra:

... na qualidade de autora, essa fusão de ficção e de autobiografia me seduz. E, na qualidade de tradutora - alguém que procura absorver e reproduzir em outra língua a presença literária de um autor - não consegui deixar de estabelecer uma relação pessoal entre "Bliss" e a figura de KM. (1988, p. 13)

Evidencia-se, aqui, a visão de tradução literária de Ana Cesar: seu compromisso é reproduzir aquilo que considera, com base em sua imersão na obra, a escrita particular de Mansfield, ou sua "presença literária”. A Nota 6 de sua dissertação, por exemplo, registra a percepção sobre a forma peculiar como a contista se relaciona com os sentimentos da personagem Bertha, tratando-os ora com sinceridade, ora com ironia. Informada por essa leitura, a tradutora afirma sentir “que tinha o 'dever' de evitar que os sentimentos de Bertha soassem ridículos":

Parece que KM brinca à beira de um abismo; creio, porém, que ela sentia um carinho por Bertha, e respeitava seus sentimentos, tornando-se, assim, uma possível identificação. E claro que ela não trata nenhum dos outros personagens com o mesmo cuidado. (1988, p. 56).

O discurso "autoral" com que Ana Cesar apresenta sua interpretação é decorrência de seu intenso envolvimento com os meandros do processo de criação.

É importante salientar que o vínculo afetivo que estabelece com as personagens e a delicadeza e "fidelidade" com que os interpreta 
e reconstrói não tolhem a liberdade da tradutora. Ao contrário, é seu comprometimento com narrativa que a leva a tomar suas próprias decisões e a fazer as intervenções que acredita atenderem aos critérios gerais que orientam a prosa poética de Mansfield. Longe de qualquer noção de tradução "literal", a tradutora defende as alterações no texto em português, como meio imprescindível para obter maior tensão sintática, harmonia sonora e clareza. Exemplo disso é sua tradução do trecho:

"And she decided from the way Miss Fulton said: 'No, Thank you, I won't smoke' that she felt it too, and was hurt."

"E pelo jeito de Miss Fulton dizer 'Não, obrigada, não quero fumar', Bertha decidiu que ela também sentia o mesmo, e estava ofendida". (CESAR, 1988, p. 80).

A comparação com uma tradução que siga o texto em inglês "mais de perto" pode nos auxiliar a perceber os efeitos promovidos pela inversão:

"And she decided from the way Miss Fulton said: 'No, Thank you, I won't smoke' that she felt it too, and was hurt."

"E decidiu, com base na forma como Miss Fulton disse: 'Não, obrigada, não vou fumar', que ela também sentia, e que estava magoada". (nossa tradução)

O cuidado artesanal com que Ana Cesar reescreve o conto faz jus à obra de Mansfield e a seu próprio talento de artista. Suas diretrizes se harmonizam com a concepção estética expressa por Mansfield em seus escritos. A pesquisadora Patrícia Alan corrobora esse argumento ao discutir o lugar da prosa de Mansfield no momento em que foi produzida: 
Nos padrões da época, o conto devia preocupar-se com a ação, o enredo, seu tema principal. A autora inova nesse sentido, já que o comprimento das frases, a sonoridade das palavras, a cadência da sentença, tudo está milimetricamente medido em sua obra, aproximando-a da poesia e corroborando o conceito de prosa poética (...). (ALAN, 2011, p. 18).

Com base em pressupostos literários muito semelhantes, Ana Cesar ouve a musicalidade da língua inglesa e a recria em português com tamanha propriedade, que se sente livre para introduzir na tradução aquilo que denominou suas próprias "idiossincrasias estilísticas" (1988, p. 14). Suas Notas explicitam esses procedimentos, ora justificando-os, ora atribuindo-os ao desejo de um melhor resultado: a repetição de uma palavra para produzir uma pausa rítmica, a alteração na adjetivação, a preferência por sons melodiosos em detrimento da precisão e o máximo cuidado com a dicção e o tom - eixos centrais de seus preceitos estéticos.

Seus comentários sobre as soluções que oferece são tão admiráveis e felizes quanto as traduções que propõe, como podemos ver na Nota 30, que pesquisadora define como uma "intervenção idiossincrática" voltada para dicção e tom, e pelo emprego de "recursos de natureza poética" (CESAR, 1988, p. 14-5) :

'.. a tall slender pear tree in fullest, richest bloom; it stood perfect...'।

'... uma árvore alta e esguia, em flor, luxuriosamente em flor, perfeita...'

A tradução desta frase e de todo o parágrafo foi muito cuidadosa, visando atingir uma precisão 'poética' e efeitos rítmicos (principalmente paralelismo rítmico). O resultado é a contração da estrutura sintática. A repetição enfática de em flor e o isolamento da palavra perfeita representam invenções para se obter o efeito desejado. (1988, p. 67) 
Ao lermos esta nota, temos a sensação de que a busca de Ana Cesar é, também ela, motivada pela palavra perfeita, palavra-em-flor.

\section{Conclusão: de "Bliss" a "Êxtase"}

Em “A criação do texto literário", Perrone-Moisés argumenta que o trabalho com a forma sensível e a forma do sentido são aspectos privilegiados da linguagem literária e defende que o compromisso do escritor é o que Roland Barthes (1977) chamou de "responsabilidade da forma". É pelo arranjo das palavras que o escritor reordena o mundo, conferindo cadência à linguagem e sugerindo afinidades entre sons e sentidos, em todos os níveis da obra, desde as grandes estruturas até "o lavor minucioso do estilo, que consiste em colocar as palavras em determinada ordem, pesando como numa balança os sons e os ritmos". (PERRONE-MOISÉS, 1990, p.106-7)

Tanto K. Mansfield como Ana Cesar parecem pautar-se por esse pressuposto. Para integrar ritmo e significado, a contista agrega musicalidade à construção de imagens e associações, visando chegar ao máximo da expressividade. Faz parte do processo de criação de Mansfield a leitura em voz alta, como se estivesse entoando uma canção.

De forma similar, Ana Cesar esclarece os procedimentos de recriação que a conduzem a Exxtase, destacando as implicações rítmicas, as ressonâncias sensuais e a sensação de prazer visual evocadas por sua tradução. A Nota 11 ilustra o "lavor minucioso" com as implicações rítmicas de suas escolhas, para transmitir a textura, a cor e o aspecto visual das frutas que formariam o arranjo de brilhantes formas arredondadas, sobre a mesa de jantar:

"Some yellow pears, smooth as silk, some white grapes covered with silver bloom and a big cluster of purple ones." "Havia peras macias lisas como seda, uvas brancas cobertas por uma floração prateada, e um cacho repleto de uvas vermelhas". (1988, p. 60) 
Os caminhos das duas escritoras se encontram e se enriquecem. Mansfield, expoente da literatura inglesa do século XX, oferece, ao leitor de língua inglesa, o conto "Bliss". Ana Cesar acompanha seus passos criativos por meio da interpretação e da emoção, e se inspira no projeto literário que norteia a contista para trazer aos leitores de língua portuguesa, Êxtase: "emoção que, ou ultrapassa a palavra felicidade - ou é mais forte do que ela... sensação de uma espécie de suprema alegria paradisíaca... emoção imaginária, cheia de força e do poder próprios do imaginário" (1988, p.50).

A maravilhosa obra de Mansfield clama por tradução e Ana Cristina Cesar não mede esforços para atender essa solicitação implícita, que é também, de certa forma, urgente. Tal é a lei da traduzibilidade, preconizada pelo filósofo alemão Walter Benjamin, em $A$ Tarefa do Tradutor (1923): as obras cuja qualidade assim o permitam, reclamam traduções, desdobramentos, sobrevida. Exxtase renova "Bliss" de forma criteriosa, por caminhos nem sempre passíveis de explicação. Emancipa-o da língua de origem, e, no traje da irredutível diferença, reapresenta-o para deleite de leitores apenas potencialmente vislumbrados em seu horizonte de expectativa inicial.

\section{Notas}

1. Outras traduções de "Bliss" disponíveis em português são: "Felicidade", de Érico Veríssimo (1940); "Felicidade", de Julieta Cupertino (1991); "Felicidade", de Maura Sardinha e Luiza Lobo (1997), "Infinita Felicidade", de Edla Van Steen e Eduardo Brandão (1984).

2. Essa postura nos faz lembrar T. S. Eliot, que valorizava, no trabalho do tradutor literário, o "olho criativo", que "não esteja bitolado por preconceitos acadêmicos” (apud CAMPOS, 1992, p. 46-7). 
3. É notável o número de estudos interessantes suscitados pelo trabalho de Ana $\mathrm{C}$. Cesar. Dentre eles, cito apenas três: "A Quarta Dimensão Do Instante": Estudo Comparativo Da Epifania Nos Contos De Virginia Woolf, Katherine Mansfield e Clarice Lispector, de Alda Maria Jesus Correia (1998); A Reescritura De Katherine Mansfield Por Érico Veríssimo: análise descritiva da tradução para o português de Bliss \& Other Stories, de Letícia De Souza Gonçalves (2008); Entreleituras de Ana Cristina Cesar e Katherine Mansfield, de Anélia Montechiari Pietrani (2011) e, da mesma autora, para livros de e sobre Ana Cristina Cesar, o site www.escritas.org/pt/estante/ana-cristina-cesar.

4. Lembremos que K. Mansfield traduziu alguns textos, como "La Chèvre de M. Seguin" de Alphonse Daudet.

\section{Referências}

ALAN, Patrícia Peter dos Santos Zachia. A Tradução da prosa poética de Katherine Mansfield em português: um estudo comparado. Tese de Doutorado. UFRGS, 2011.

CESAR, Ana Cristina. Escritos da Inglaterra. Tradução de Maria Luiza Cesar. São Paulo: Brasiliense, 1988, 176 pgs.

BORGES, Jorge Luis. As Versões Homéricas. In: Discussão. Tradução de Claudio Fornari. São Paulo: Difel, 1986, p. 71-78.

CAMPOS, Haroldo. "Da tradução como criação e como crítica". In: Metalinguagem. São Paulo: Cultrix, [1976] 1992, p. 31-48.

GOMES, Adriana de Freitas. Ana Cristina Cesar - a tradução como exercício de recriação. In: Revista Gatilho, Juiz de Fora: Ed. UFJF. Ano II, Volume 4, set. 2006. Disponível em: http://www.ufff.br/revistagatilho/files/2009/12/AdrianaFreitasGomes.pdf. Acesso em 08 jan. 2015. 
. OLIVEIRA, Maria Clara Castellões de. Ana Cristina Cesar, tradutora de Katherine Mansfield. In: Ipotesi, Juiz de Fora, v. 13, n. 1, jan./jul. 2009, p. $41-56$.

MANSFIELD, Katherine. Bliss and Other Stories. UK: Penguin Books Ltd, 2001, 229 pgs.

ro: Revan, 1996, 285pgs.

. Diário \& Cartas. Tradução de Julieta Cupertino. Rio de Janei-

PAES, José Paulo. Bandeira tradutor ou o esquizofrênico incompleto. In: Tradução. A ponte necessária. São Paulo: Ed. Ática, 1990, p. 55-66.

PAZ, Octavio. Tradução: literatura e literalidade. Edição bilíngue. Ensaio traduzido por Doralice Alves de Queiroz. Belo Horizonte. FALE/UFMG, 2009. Disponível em: http://www.letras.ufmg.br/vivavoz/data1/arquivos/traducao2ed-site. pdf. Acesso em 20 jan.2015.

PERRONE-MOISÉS Leyla. "A Criação do Texto Literário". In: Flores da escrivaninha. São Paulo, Companhia das Letras, 1990, p. 100-110.

PRADO, Célia Luiza Andrade - Tradução, Paródia e paráfrase: as reescrituras poéticas de Manuel Bandeira. In: TradTerm 18, 2011.1, p. 155-178. Disponível em: www.usp.br/tradterm. Acesso em 21 jan. 2015.

SOUZA, Carlos Eduardo Siqueira Ferreira de. A lírica fragmentária de Ana Cristina Cesar. São Paulo: EDUC, 2010, 198 pgs.

Recebido em: 02/01/2015

Aceito em: 10/03/2015 